Erratum

\title{
Erratum to "Epac1 Restores Normal Insulin Signaling through a Reduction in Inflammatory Cytokines"
}

\author{
Elizabeth Curtiss, ${ }^{1}$ Youde Jiang, ${ }^{1}$ Li Liu, ${ }^{1}$ Claire Hawthorne, ${ }^{1}$ Jessica Zhang, \\ and Jena J. Steinle $\mathbb{i D}^{1,2}$ \\ ${ }^{1}$ Department of Anatomy and Cell Biology, Wayne State University School of Medicine, Detroit, MI, USA \\ ${ }^{2}$ Department of Ophthalmology, Wayne State University School of Medicine, Detroit, MI, USA \\ Correspondence should be addressed to Jena J. Steinle; jsteinle@med.wayne.edu
}

Received 19 May 2019; Accepted 27 May 2019; Published 18 June 2019

Copyright (c) 2019 Elizabeth Curtiss et al. This is an open access article distributed under the Creative Commons Attribution License, which permits unrestricted use, distribution, and reproduction in any medium, provided the original work is properly cited.

In the article titled "Epac1 Restores Normal Insulin Signaling through a Reduction in Inflammatory Cytokines" [1], it was found that the western blots in Figures 5(b) and 5(c) were duplicated. This error happened during the production process. The corrected figure is shown below. 

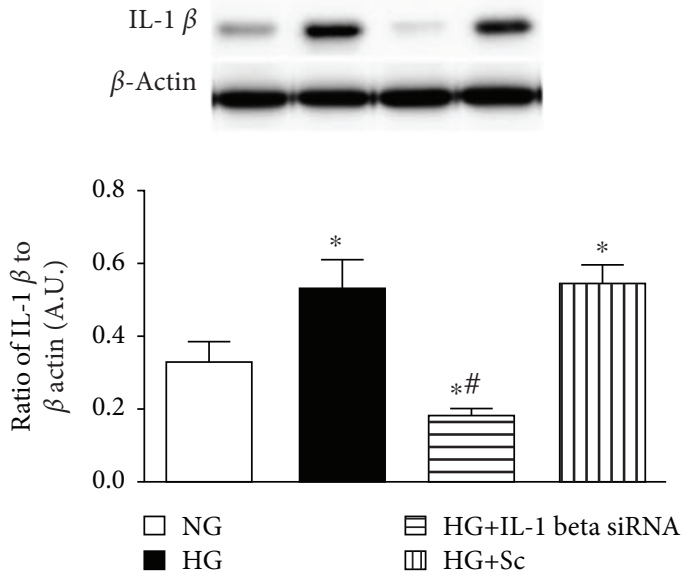

(a)
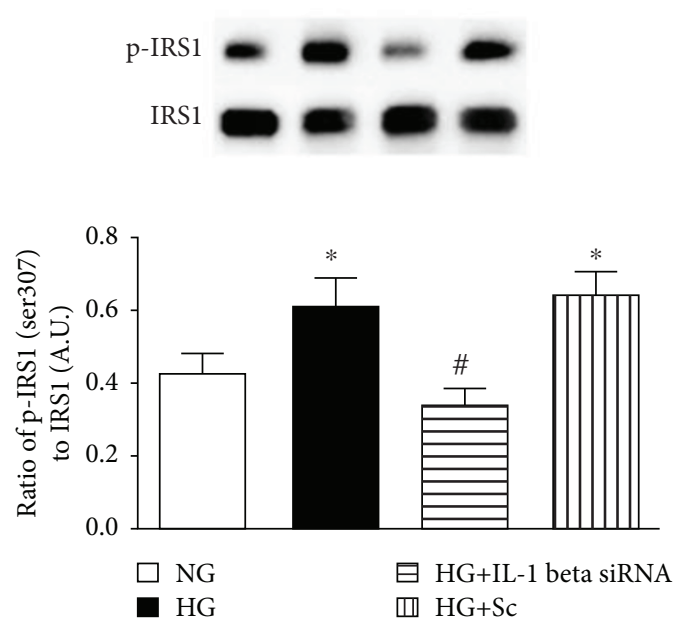

(c)
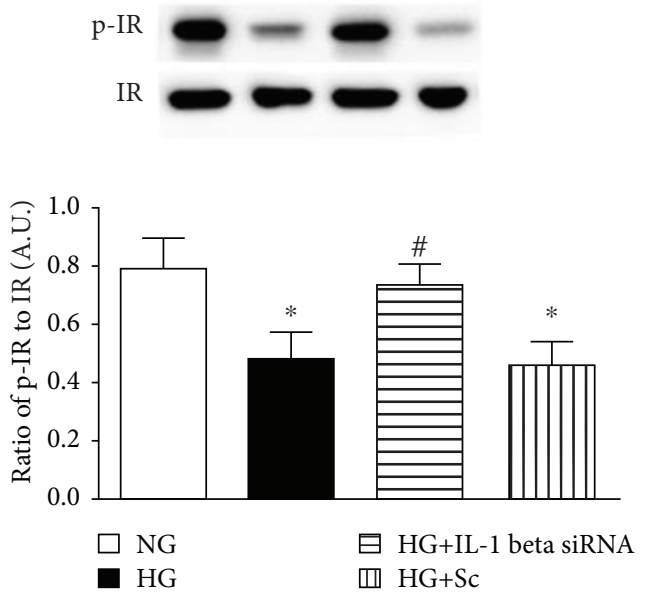

(b)
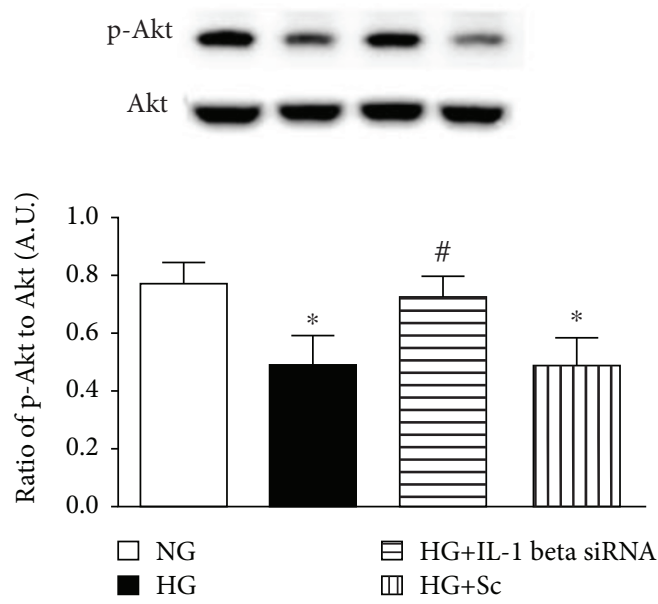

(d)

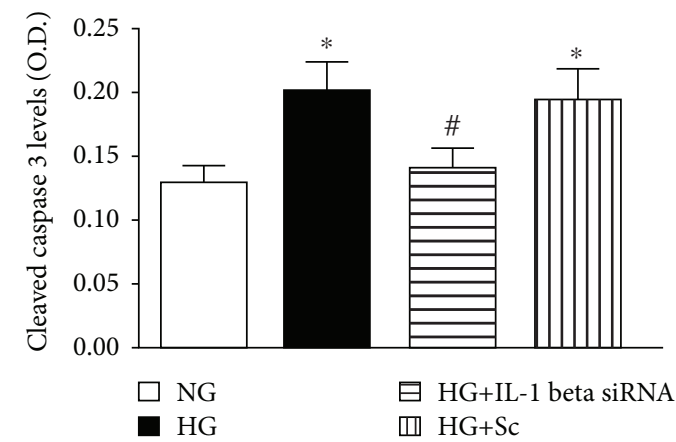

(e)

Figure 5: (a) Western blotting for the ratio of IL- $1 \beta$ siRNA to $\beta$-actin in REC grown in normal glucose (NG) and high glucose (HG). Some REC grown in HG were transfected with IL-1 $\beta$ siRNA or scrambled siRNA (sc). (b-d) Western blotting for the ratio of phosphorylated insulin receptor on tyrosine 1150/1151 (p-IR), IRS-1Ser307 (p-IRS-1), and Akt (p-Akt) to total protein. (e) ELISA results for cleaved caspase 3 levels. ${ }^{*} P<0.05$ versus NG, ${ }^{\#} P<0.05$ versus HG. $N=4$ or 5 for all groups. Data are mean \pm SEM.

\section{References}

[1] E. Curtiss, Y. Jiang, L. Liu, C. Hawthorne, J. Zhang, and J. J. Steinle, "Epac1 restores normal insulin signaling through a reduction in inflammatory cytokines," Mediators of Inflammation, vol. 2018, Article ID 3809092, 9 pages, 2018. 


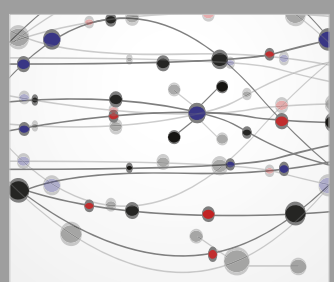

The Scientific World Journal
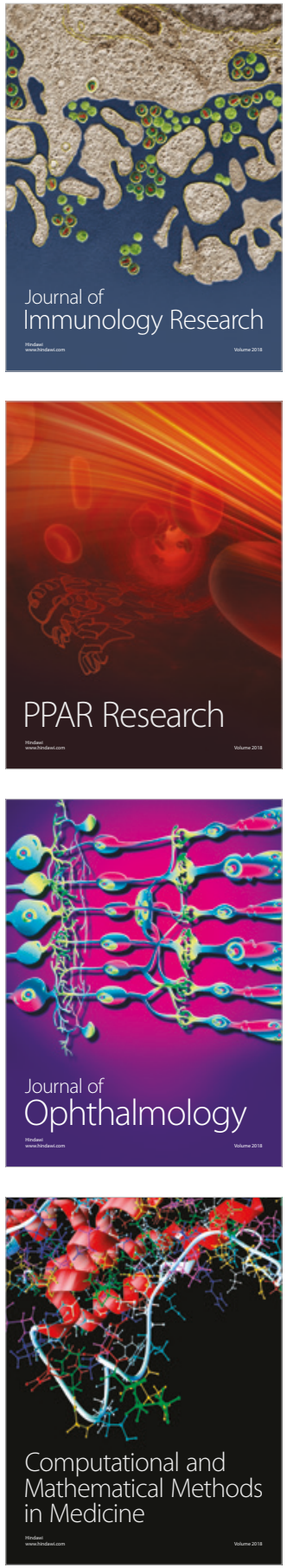

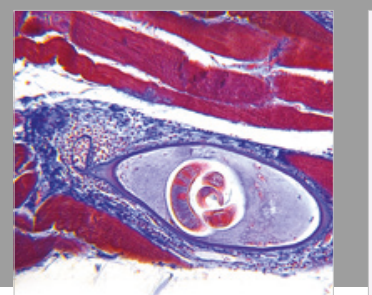

Gastroenterology Research and Practice

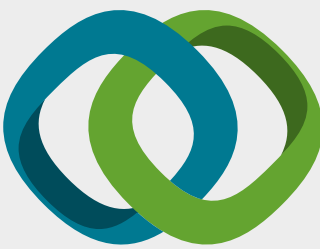

\section{Hindawi}

Submit your manuscripts at

www.hindawi.com
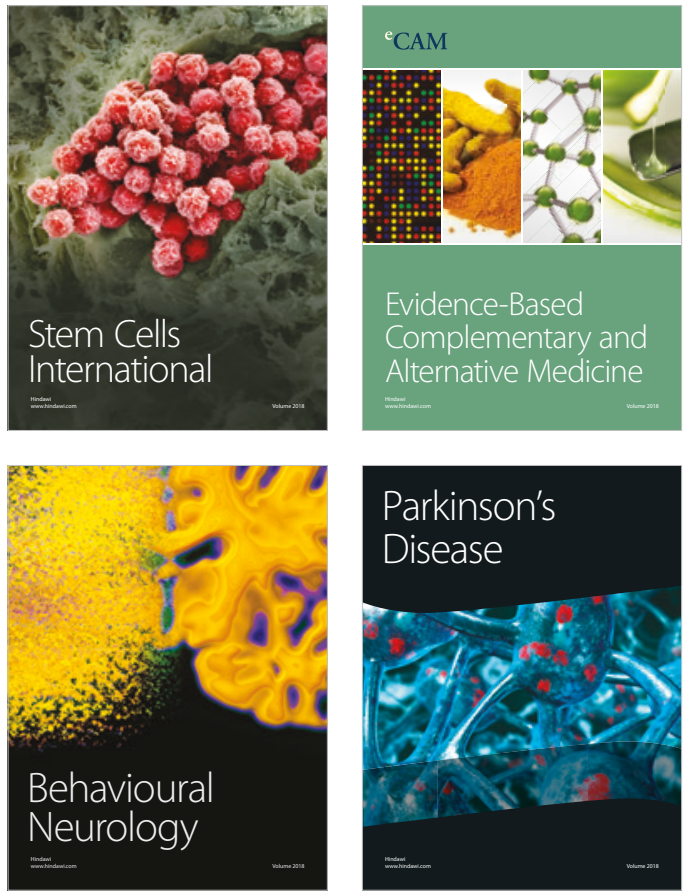

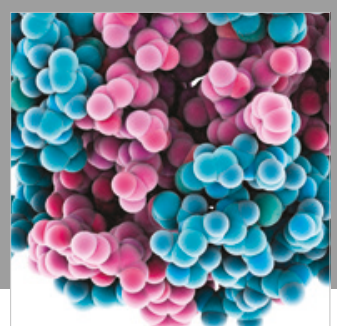

ournal of

Diabetes Research

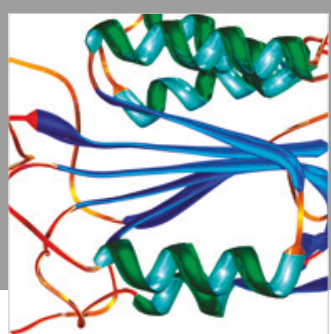

Disease Markers
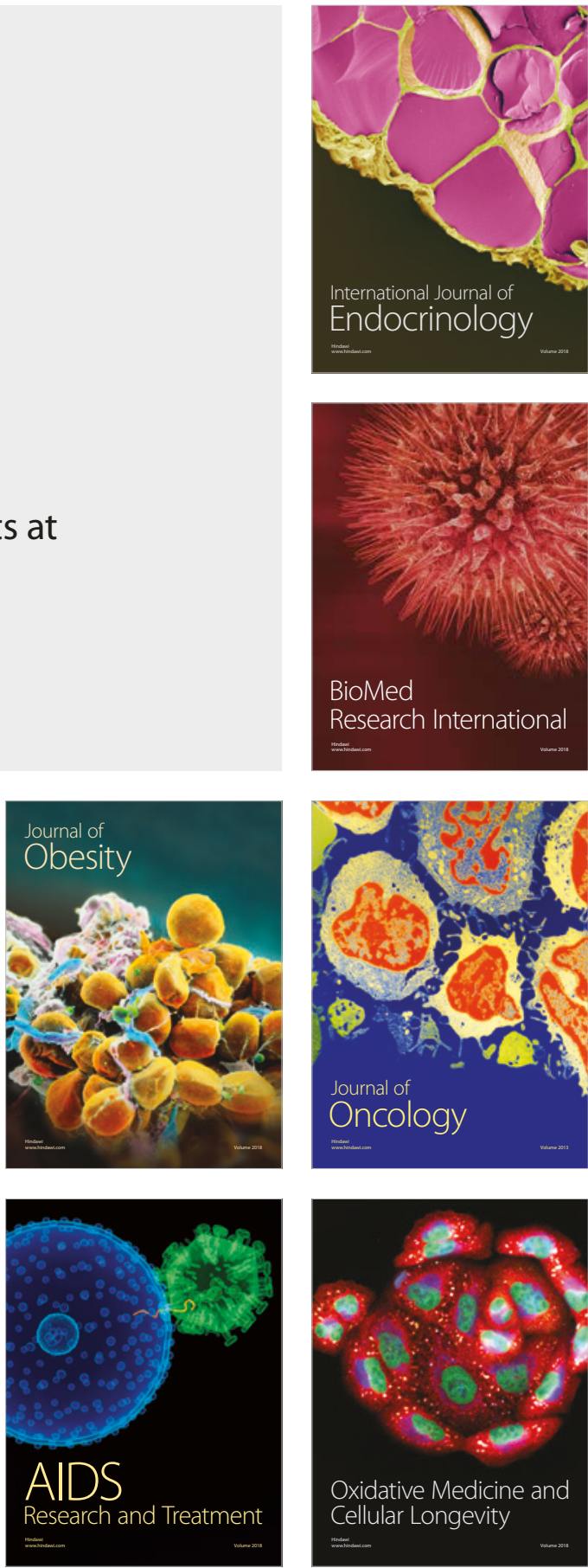